\title{
WHO global meeting to accelerate progress on SDG target 3.4 on noncommunicable diseases and mental health ${ }^{1}$
}

Citation: WHO global meeting to accelerate progress on SDG target 3.4 on noncommunicable diseases and mental health. East Mediterr Health J. 2021;27(5):524-525. https://doi.org/10.26719/2021.27.5.524

Copyright ( ) World Health Organization (WHO) 2021. Open Access. Some rights reserved. This work is available under the CC BY-NC-SA 3.0 IGO license (https://creativecommons.org/licenses/by-nc-sa/3.o/igo).

\section{Introduction}

The World Health Organization Region for the Eastern Mediterranean is facing a double burden of the prevalence of malnutrition as well as overweight, obesity and diet-related noncommunicable diseases (NCDs) (1). For this reason, a new strategy on nutrition for the Eastern Mediterranean Region 2020-2030 (2) has been developed with input from Member States and United Nations (UN) partners and was adopted by the WHO Regional Committee for the Eastern Mediterranean in October 2019 (3). To address this issue, a global meeting took place in Muscat, Oman, from 9 to 12 December 2019 (4), which examined ways to accelerate progress on Sustainable Development Goal (SDG) target 3.4 on noncommunicable diseases and mental health (5). At the meeting, a regional side meeting on nutrition was organized to launch a new strategy on nutrition for the Eastern Mediterranean Region 20202030 (2). Country representatives from 17 Member States took part, along with WHO staff from the WHO Regional Office for the Eastern Mediterranean, WHO country offices, and expert consultants.

The objectives of the meeting were to:

- Support countries to operationalize a current national nutrition strategy and plan of action in order to achieve global and regional targets; and

- Provide a framework for countries to accelerate efforts to improve nutrition and food security through six key action areas of the UN Decade of Action on Nutrition (6).

\section{Summary of discussions}

A number of common challenges facing countries in implementing actions to improve nutrition were identified. Food and nutrition surveillance was one challenge shared by many countries, whereby the tendency for countries to prioritize representative national surveys was highlighted, however these require extensive resources and the process can be lengthy. Another key challenge relates to being able to monitor and evaluate the implementa- tion and impact of the regional strategy and the priority actions highlighted within it. There were several other areas where the need for support to build capacity and/or technical guidance were identified. These include implementation issues, such as the drafting of legislations and design of policy measures to tackle the double burden of malnutrition. There were also challenges relating to communication and advocacy, including the difficulty in convincing other sectors/stakeholders of the importance of actions to improve nutrition, how to deal with opposition from groups of vested interests, and persuade donors of the need to invest in addressing all forms of malnutrition. The general need to raise awareness of these issues at all levels among policy-makers, professionals and the general public was recognized.

\section{Recommendations}

\section{To WHO}

- Implementing and strengthening food and nutrition surveillance systems;

- developing food-based dietary guidelines;

- developing and updating food composition databases; and

- developing guidance for general practitioners and other primary care professionals on the early identification and management of nutritional problems.

To Member States

- Improving nutrition education and introducing certification of nutrition practitioners;

- implementing the "International Code of Marketing of Breast-milk Substitutes" legislation;

- implementing programmes to deal with the high prevalence of acute malnutrition if present; and

- reviewing current plans for WHO country support in order to identify opportunities to add specific actions relating to identified needs.

This summary is extracted from the report on the WHO global meeting to accelerate progress on SDG target 3.4 on noncommunicable diseases and mental health: Side meeting on nutrition, Muscat, Oman, 12 December 2019 (https://www.who.int/publications/i/item/9789240004962). 


\section{References}

1. World Health Organization Regional Office for the Eastern Mediterranean (WHO/EMRO). WHO global meeting to accelerate progress on SDG target 3.4 on noncommunicable diseases and mental health. Cairo: WHO/EMRO; 2020 (https://www.who.int/ publications/i/item/9789240004962).

2. World Health Organization Regional Office for the Eastern Mediterranean (WHO/EMRO). Strategy on nutrition for the Eastern Mediterranean Region 2020-2030. Cairo: WHO/EMRO; 2019 (https://apps.who.int/iris/handle/10665/330059).

3. World Health Organization Regional Office for the Eastern Mediterranean (WHO/EMRO). The 66th session of the WHO Regional Committee for the Eastern Mediterranean opens in Tehran. Cairo: WHO/EMRO; 2019 (http://www.emro.who.int/media/news/ the-66th-session-of-the-who-regional-committee-for-the-eastern-mediterranean-opens-in-tehran.html).

4. World Health Organization Regional Office for the Eastern Mediterranean (WHO/EMRO). WHO global meeting to accelerate progress on SDG target 3.4 on noncommunicable diseases and mental health: Side meeting on nutrition, Muscat, Oman, 12 December 2019.Cairo: WHO/EMRO; 2020 (https://www.who.int/publications/i/item/9789240004962).

5. United Nations. Target 3.4: By 2030, reduce by one third premature mortality from non-communicable diseases through prevention and treatment and promote mental health and well-being. New York: United Nations; 2016 (https://unstats.un.org/sdgs/ metadata? $T$ ext $=\&$ Goal $=3 \&$ Target $=3.4$ ).

6. United Nations. Decade of action on nutrition. New York: United Nations; 2016 (https://www.un.org/nutrition/). 